\title{
Psychiatric in-patients, violence and the criminal justice system
}

\author{
Simon Wilson, ${ }^{1}$ Kevin Murray, ${ }^{2}$ Mike Harris, ${ }^{3}$ Michael Brown ${ }^{4}$
}

The Psychiatrist (2012), 36, 41-44, doi: 10.1192/pb.bp.111.034876

${ }^{1}$ Oxleas NHS Foundation Trust and Institute of Psychiatry, London; ${ }^{2}$ West London Mental Health NHS Trust, Broadmoor Hospital, Crowthorne; ${ }^{3}$ Rampton Hospital, Retford;

${ }^{4}$ Smethwick Police Station, Sandwell

Correspondence to Simon Wilson (simon.wilson@kcl.ac.uk)

First received 6 Apr 2011, final revision 30 Sep 2011, accepted 17 Oct 2011
Summary There is ambivalence about prosecuting psychiatric in-patients for violent offences. This ambivalence is reflected in the Memorandum of Understanding that exists between the Crown Prosecution Service and the NHS Security Management Service. This has led to an unwelcome change in practice when the police ask for information from an individual's consultant psychiatrist, the police requesting information about the individual's cognitive abilities at the time of the alleged offence and using this to make decisions about prosecution. However, there is also guidance on this area from other sources. We describe this and make further suggestions for dealing with these requests.

Declaration of interest None
This paper arises from discussion in the Executive Committee of the Royal College of Psychiatrists' Faculty of Forensic Psychiatry (however, the views given here are ours and do not necessarily reflect the views or policies of our employers or the College). We are three senior forensic psychiatrists and a police officer concerned about the difficulty of engaging the criminal justice system in response to apparently criminal acts committed by patients against staff or other patients in psychiatric hospitals, and the risk that doctors may be asked to make judgements about their patients that seem to pre-empt questions that are for courts.

We know that mental health staff are likely to be assaulted by their patients, ${ }^{1,2}$ and we also know that this violence is very rarely reported to the police $-4 \%$ of incidents being reported in one study. ${ }^{3}$ However, assaults by psychiatric patients have always been a difficult area. On the one hand there are welfare-oriented policies suggesting that it is better not to prosecute individuals with mental disorders - they cannot be held fully responsible for their (criminal) behaviours, they require diversion into treatment rather than punishment and the criminal justice system may be harmful to them. On the other hand there are the arguments that prosecution may be beneficial in itself (therapeutic jurisprudence ${ }^{4}$ ), that it treats people with mental disorders the same as people without mental disorders (not giving them carte blanche to offend on the basis of a status), that it improves future risk management ${ }^{5}$ and that it may allow new treatment interventions (such as a disposal under the criminal parts of mental health legislation) that are more effective. Although some staff may consider that there are ethical problems in providing statements to the police and supporting prosecution, there is a need to balance sometimes competing ethical principles - justice, respect for autonomy, beneficence and non-maleficence. In most cases, we believe that the overall balance is in favour of prosecution (or other criminal justice intervention, as the criminal justice system has a range of other potentially helpful interventions in such cases, including community resolutions, cautions and fixed penalty tickets, that do not require charging and prosecution). We set out the reasons for this in more detail below. This ambivalence about prosecuting mentally disordered offenders is longstanding. ${ }^{6}$ And of course all arguments about the propriety of reporting assaults on staff in order for a prosecution to be considered apply at least as forcefully in respect of reporting assaults on other patients, who have far fewer opportunities to seek the protection of the law.

This ambivalence appears to have a more recent manifestation. If a psychiatric in-patient commits an assault and the clinical team report this to the police in order to consider a prosecution, the Crown Prosecution Service (CPS) have begun to ask for a statement about the individual's mental state at the time of the alleged offence, specifically including whether or not they knew what they were doing and the difference between right and wrong. This is in addition to the usual requirements for a statement about their fitness to be detained in police custody and interviewed, and some bare facts about their diagnosis, treatment and detained status. We were unable to find anything about this change in the literature, but when we circulated the issue to forensic psychiatric colleagues via the Royal College of Psychiatrists' Care Quality Network, we discovered that it had been happening around the country. This raises the following three concerns.

(1) It seems to be using trial issues (the future prospect of an insanity defence) routinely to determine whether to charge a person, something that is not done for people 
who are not mentally ill, and is therefore stigmatising and unfair. It is a massive misconception that fitness to plead or stand trial should be anticipated at the point of making statutory charging decisions - it is simply not relevant to the decision.

(2) These statements are usually collected from the person's 'responsible clinician' who probably does not have the level of expertise in these matters that would be expected were the issues addressed in the normal way at trial by an expert witness, and would be subject to testing by cross-examination. This is conflating expert and professional witness testimony. Again, this seems potentially unjust.

(3) The sense is that if the person did not know what they were doing or the difference between right and wrong, then they are unlikely to be charged. However, even a not guilty by reason of insanity finding at court would offer the prospect of a criminal justice intervention (such as a restricted hospital order) that may make an enormous difference to that person's future clinical management and likelihood of reoffending. Access to this intervention has been reduced.

Where has this come from and what should psychiatrists do when asked for such a statement? And why is it important to use the criminal justice system when violence has occurred? We try to deal with these questions below.

\section{The Code for Crown Prosecutors}

The CPS use a two-stage process when deciding whether to prosecute. ${ }^{7}$ First, the evidential stage, where 'prosecutors must be satisfied that there is sufficient evidence to provide a realistic prospect of conviction' (Section 4.5). ${ }^{7}$ Second, the public interest test. The CPS's webpage on mentally disordered offenders states 'There is no presumption either in favour of or against the prosecution of a mentally disordered offender. Each case must be considered on its merits, taking into account all available information about any disorder, and its relevance to the offence, in addition to the principles set out in the Code for Crown Prosecutors' 8 Section 4.16(d) of the Code states that if 'the offence was committed against a person serving the public (for example,... a health or social welfare professional)' this would be a common public interest factor that should increase the likelihood of prosecution. ${ }^{7}$ The Code goes on to describe in general terms the balance to be struck between the need for diversion and treatment, and prosecuting to safeguard the public, and the need to consider issues of mens rea, and whether the person's ability to form the necessary mens rea might have been compromised by their mental disorder. The CPS recommends that 'medical reports from the responsible clinician to explain the nature and degree of the disorder or disability, and any relationship between the disorder and the treatment and behaviour of the offender, ${ }^{8}$ be sought, and also that, if the victim is a member of staff, the Memorandum of Understanding between the NHS Counter Fraud and Security Management Service and the Crown Prosecution Service 9 should be followed.

\section{The Memorandum of Understanding between the NHS Counter Fraud and Security Management Service and the Crown Prosecution Service}

Paragraph 11.9 of this document is far more proscriptive than the Code for Crown Prosecutors, and gives the following guidance (the emphasis is ours):

'The CPS will need information and evidence regarding the mental disorder at the earliest opportunity in order to properly review a case involving a mentally disordered suspect. This will ensure that appropriate cases are properly progressed and will prevent any arbitrary decisions from being taken regarding a person's mental health or capacity without the decision-maker obtaining the fullest information. Such information should include, where appropriate, details regarding the suspect's capacity at the time of the alleged offence(s), and their fitness to be arrested, detained, interviewed and charged, and to plead. Further information should also be requested in relation to whether he or she has acted in a similar manner before, the likelihood of further offences, and the mental health status and treatment of the alleged offender. A prompt response will be required and the NHS SMS [security management service] should assist the police and CPS in obtaining the information from the relevant NHS body when required. The CPS should immediately notify the NHS SMS if it is having difficulty in obtaining any information relevant to its review of the case. The information that may be requested includes:

- medical reports from appropriate clinician or responsible medical officers to explain the nature and degree of the disorder and the treatment and behaviour of the patient

- any other relevant information from other hospital staff about the treatment and behaviour of the patient, including the treatment regime, history of similar and recent violent or otherwise offending behaviour

- information about an offender's status in hospital - whether voluntary or detained under Section 2 or Section 3 (civil procedures) or under Section 37 (Court Hospital Order) and whether there is a restriction order under Section 41 attached to the Section 37 order

- evidence from a suitably qualified clinician about the offender's state of mind at the time of the incident, including whether the patient knew what he or she was doing, whether the patient knew that what he or she was doing was wrong and, if not, whether the lack of knowledge was attributable to his or her disorder and/or any medication or other treatment for his or her disorder

- evidence regarding the person's fitness to plead.9

\section{Guidance on Responding to People with Mental III Health or Learning Disabilities}

More recently the National Policing Improvement Agency have published guidance relevant to the area of responding to people with mental ill health or intellectual disabilities (referred to as people with learning disability by UK health services). ${ }^{10}$ This is more in line with our views about best practice in this area. Paragraph 4.1.6 reads:

'In fulfilling the police role in preventing and investigation crime and tackling offending behaviour, offenders or suspects with mental ill health or learning disabilities should, generally, be dealt with through the criminal justice system as any other offenders or suspects are.'

Paragraph 7.7 deals specifically with the issues of 'criminal offences in health and social care settings' and suggests that the normal investigative procedures should be followed, together with encouraging local policies between the police and health and social services. Paragraph 7.10 refers to the CPS Code for Crown Prosecutors and suggests that the following information would assist prosecutors in making decisions about prosecution: 
'Whether the offence is serious and relates to public protection or relates to a minor infringement of the law;

Whether the offence is part of a series of offences or a pattern of offending behaviour which requires intervention by the criminal justice system for the protection of the public;

Whether the mental health issue has affected the individual's criminal responsibility for his or her actions;

The views and personal statement of the victim (where appropriate);

The views of other agencies and whether the individual's needs would be better addressed by an appropriate health or social care response. ${ }^{, 10}$

\section{The importance of using the criminal justice system when an assault has been committed}

Prosecuting patients for acts of non-trivial violence is important. Not to do so, implies, unhelpfully, that we have overall responsibility for all of our patients' actions. The clinical issues around the management of patients following an assault - the degree of restriction required for the safe management of the ward, the possible need for transfer to another ward at least temporarily, etc. - remain the proper responsibility of the clinicians concerned, but the wider Crown responsibility for the maintenance of law and order cannot be discharged by the exercise of clinical responsibility alone.

\section{The fallacy of clinical omnipotence}

This attitude may also be discerned within clinical services, either at individual practitioner or at a team level, where an assault is experienced as a failure of professional care - 'If I/ we were better at my/our job it wouldn't have happened'. Such assumptions, implicit or explicit, conscious or unconscious, are identical to attitudes to domestic violence a generation ago, which contributed to the failure to investigate, prosecute and convict the perpetrators of such violence, and which have now largely been turned around as a consequence of years of campaigning.

\section{The benefits of reporting all non-trivial assaults to the police for possible prosecution}

There are demonstrable benefits for our patients, for all of our staff including ourselves, and for the wider community in the adoption of a policy whereby all non-trivial assaults are reported to the police, are investigated and are assessed against the CPS criteria as to whether prosecution should proceed in exactly the same way as would happen if such an incident occurred outside of hospital.

\section{The benefits for our patients}

The failure to invoke the ordinary external sanctions of the police and the courts following an assault amounts to a failure to reinforce to the assaultative patient the unacceptability of such behaviour. Although a change of ward may be significant, it has much less significance when a First Tier Tribunal (Mental Health) is considering a case than does the fact of a criminal conviction. By failing to invoke the ordinary external sanctions, we are failing to use a powerful learning model to discourage aggressive behaviour. This may be of particular benefit where clinical assessment of risk indicates a continuing concern around resort to violence, but the patient concerned remains reluctant to acknowledge the seriousness of such events. Although it might be argued that the most unwell of our patients are impervious to the experience of prosecution as a learning model, the statutes dealing with defendants who are unfit to plead or who are found to be not guilty by reason of insanity apply in these instances - and allow the consistent application of a standard of intolerance for violent acts.

Of course, the most frequent victims of assaults by patients are other patients. Any measures that we can take to reduce the frequency of assaults committed by inpatients will therefore have a direct bearing on the safety of the entire patient group. The benefit to non-assaultative patients is obvious. However, it should also be borne in mind that those patients who commit assaults may be most likely also to be assaulted themselves, and the general reduction in the incidence of assaults will also benefit the assaultative patients directly in terms of their own safety.

\section{The benefits for our staff}

In respect of staff, the immediate and obvious benefit would be that of working in a safer service; this needs no further explanation. However, in addition to that immediate benefit, there would be additional gains in terms of having clearer responsibilities, with established effective lines of communication with the police so that it was not a matter of 'reinventing the wheel' on each and every occasion when this problem arose. A change of culture within services so that an assault was not experienced as a failure may also be beneficial in terms of morale and staff retention.

\section{The benefits for the wider community}

In respect of the wider community, the immediate benefit would be the better identification of those patients who pose a high level of risk but are currently detained only under civil or otherwise unrestricted orders of the Mental Health Act. Following prosecution, there is the opportunity to attach a restriction order to a hospital order, to ensure that the public interest is properly considered in respect of decisions about transfer or discharge. This will incidentally have the effect of committing services to remaining in contact with such high-risk individuals beyond the end of hospital in-patient care.

Across the community of mental health services, the improved notification of serious incidents leading to prosecution can only be helpful in so far as it offers the opportunity for shared learning between the services dealing with problematic individuals, and in particular for services to identify whether their performance was at the level to be hoped for, or whether there were lessons to be learned from neighbours.

\section{The benefits for the police service}

Police services who have invested in local neighbourhood officers to effectively manage reports of violence by inpatients - by building a working knowledge of out-of-court as well as prosecution-based responses to violence - have found themselves able to actually reduce levels of violence 
in hospitals and have identified very effective, streamlined ways to manage those reports that are received, saving officer time. Close partnership arrangements also allow for earlier and often informal dialogue between clinical and criminal justice staff to jointly identify a suitable response to an incident, based upon established trust around what a good policing or justice response may look like. In some areas, this has also included liaison arrangements with CPS lawyers whereby the same lawyer is used for all psychiatric in-patient cases.

Trust and close working allow for more confident identification of those rare opportunities where it is necessary to influence the prosecution of patients because previous convictions - not necessarily known to clinical professionals if individuals are detained under civil mental health legislation - indicate that broader public protection arrangements may be necessary. This may take the form of attempting to secure restricted hospital orders, for example, not only in relation to serious offences, but also in relation to less serious incidents that give rise for concerns of a 'risk of serious harm' to the public. Such orders render patients liable to 'multi-agency public protection arrangements' for closer monitoring upon release from in-patient care.

\section{A suggested approach}

All non-trivial violence by psychiatric patients should be reported to the police. It will be appropriate to provide a statement about their fitness to be detained in police custody and interviewed (and a willingness to discuss this with the custody officer and forensic medical examiner (FME) where there is disagreement), and some bare facts about their diagnosis, treatment and detained status. Unless a patient's arrest and removal to a police station is immediately necessary because of ongoing violence that continues to place others at risk, there is much merit to be had in conducting formal suspect interviews in the hospital, without resorting to an arrest. First, it is logistically much easier. Second, we remove the possibility of conflict between psychiatrist and FME. Third, solicitors, appropriate adults, FMEs and other necessary participants become easier to organise, often less urgently than if someone is arrested, and it allows more comprehensive discussion prior to interview about the best way forward.

It will rarely be appropriate to deal with questions about whether they knew the difference between right and wrong or what they were doing at the time of the alleged offence. Instead, a skeleton statement may be helpful, suitably modified for the case at hand, rehearsing the reasons why a prosecution is in the public interest, and online supplement DS1 offers a suggested template.

The use of a skeleton argument like this would provide greater support to individual clinical teams both in the National Health Service (NHS) and the independent sector in attempting to deal with the police and CPS, and provides a clear message, with the support of their employing NHS trust (or company, in the case of an independent hospital), that assaults on staff are not tolerated. It is also in line with the Code for Crown Prosecutors ${ }^{7,8}$ and in the National Policing Improvement Agency's latest guidance. ${ }^{10}$ The Memorandum of Understanding between the NHS and $\mathrm{CPS}^{9}$ does not, in our view, offer good guidance on this area and should not be followed. In any event this does not apply to independent hospitals. The West Midlands Police have been pioneering in attempting to deal with this issue from a policing perspective, and online supplement DS2 offers a suggested template for police officers investigating such incidents, and was developed jointly between the police, CPS and local forensic mental health service. This is intended to be a supplementary document to a generic Data Protection request, of the type the police would send to any agency where they wanted information in pursuance of a criminal investigation. It would be attached to the Data Protection Act information request form and clearly badged as a legal application under Section 29(3) of the Data Protection Act. This then means information capable of disclosure according to the principles laid down in Schedules 2 and 3 should be disclosed and it removes discretion as to whether it should be disclosed, save to the extent that there is doubt about the information being covered by the schedules.

\section{Acknowledgements}

We thank Dr Keith Rix for his helpful advice and comments on an earlier draft of this paper.

\section{About the authors}

Dr Simon Wilson is a consultant forensic psychiatrist and honorary senior lecturer at the Oxleas NHS Foundation Trust and Institute of Psychiatry, Department of Forensic \& Neurodevelopmental Science, Institute of Psychiatry, London. Dr Kevin Murray is a consultant forensic psychiatrist and clinical director at the West London Mental Health NHS Trust, Broadmoor Hospital, Crowthorne. Dr Mike Harris is a consultant forensic psychiatrist and executive director of forensic services, Chief Officer for High Secure Care, Rampton Hospital, Retford. Michael Brown is a criminal justice inspector at Smethwick Police Station, Sandwell, UK

\section{References}

1 Health Policy and Economic Research Unit. Violence at Work: The Experience of UK Doctors. British Medical Association, 2003.

2 Health and Safety Executive. Violence at Work: New Findings from the British Crime Survey 2000. Home Office \& HSE, 2001.

3 Young C, Brady J, labal N, Brown F. Prosecution of physical assaults by psychiatric in-patients in Northern Ireland. Psychiatr Bull 2009; 33: 416-9.

4 Wexler DB. Therapeutic jurisprudence and the criminal courts. William Mary Law Rev 1993; 35: 279-99.

5 Ritchie JH, Dick D, Lingham R. The Report of the Inquiry into the Care and Treatment of Christopher Clunis. HMSO, 1994.

6 Eastman N, Mullins M. Prosecuting the mentally disordered. J Forens Psychiatry 1999; 10: 497-501.

7 Crown Prosecution Service. The Code for Crown Prosecutors. CPS Policy Directorate, 2010.

8 Crown Prosecution Service. Mentally Disordered Offenders. CPS, 2010 (http://www.cps.gov.uk/legal/I_to_o/mentally_disordered_offenders).

9 Crown Prosecution Service, NHS Security Management Service (CPS \& SMS). Memorandum of Understanding between the NHS Counter Fraud and Security Management Service and the Crown Prosecution Service. CPS \& SMS, 2008 (http://www.cps.gov.uk/publications/agencies/ mounhs.html).

10 National Policing Improvement Agency. Guidance on Responding to People with Mental III Health or Learning Disabilities. ACPO NPIA, 2010 (http://www.npia.police.uk/en/docs/Mental_ill_Health.pdf). 